\title{
Soil Moisture Effects on Entomopathogenic Nematodes
}

\author{
JENNIFER A. GRANT ${ }^{1}$ AND MICHAEL G. VILLANI ${ }^{2}$ \\ Department of Entomology, Cornell University, NYSAES, Geneva, NY 14456-0462
}

Environ. Entomol. 32(1): 80-87 (2003)

\begin{abstract}
The effect of soil moisture on entomopathogenic nematode virulence was examined in the laboratory. Objectives were to determine the virulence of several species and isolates of entomopathogenic nematodes at various soil moisture contents and temperatures, and after fluctuations in soil moisture. Studies included up to five isolates of entomopathogenic nematodes: Heterorhabditis bacteriophora Poinar (Oswego and Tuscarora strains), Steinernema glaseri (Steiner) (NC1 strain), S. feltiae (Filipjev) (Biosys 369 strain), and S. carpocapsae (Weiser) (NY001 strain). Nematodes were applied to sandy loam soils ranging in soil moisture content from below the permanent wilting point of plants to near saturation. In all experiments, a rainfall or irrigation event was simulated by adding water to rehydrate soils to high moisture levels (near saturation). Nematode virulence was evaluated periodically by measuring insect mortality in Galleria mellonella (L.) larval bioassays, before and after rehydration. Nematode virulence increased with soil moisture content for all species and isolates tested. Our studies demonstrated that the virulence of entomopathogenic nematodes in low moisture conditions could be restored by rehydrating the soil. Insect mortality was generally low in lowmoisture, nematode-infested soils before rehydration, but increased to high levels posthydration. Moisture effects were evident from the onset of each experiment, whereas the effect of soil temperature on nematode-induced insect mortality was delayed and nonsignificant until $14 \mathrm{wk}$ after the initiation of the third experiment.
\end{abstract}

KEY WORDS entomopathogenic nematodes, soil moisture, Heterorhabditis bacteriophora, Steinernema spp., rehydration, biological control

ENTOMOPATHOGENIC NEMATODES ARE well adapted to infect insect pests living in soil, and have the potential to be important biological control agents in a variety of ornamental and crop production systems (Kaya and Gaugler 1993, Georgis and Manweiler 1994, Gaugler et al. 1997). Despite intensive research efforts, field efficacy of entomopathogenic nematodes has been variable, which has hindered acceptance by pest managers (Gaugler 1988, Klein 1990, Smith 1999). More consistent results have been achieved through education of users on proper application techniques, the development of improved formulation and application techniques, and appropriate selection of nematode species and strains for particular uses (Gaugler et al. 1997). Of equal importance is the impact of the soil and agronomic environment on nematode ecology, which must be better understood before nematodes can be used as a reliable pest management tactic.

Nematode performance may be influenced by many abiotic environmental factors including soil moisture (Koppenhöfer et al. 1995, Fujiie et al. 1996), temperature (Kung et al. 1991, Griffin 1993, Grewal et al. 1994), light (Gaugler et al. 1992, Fujiie and Yokoyama

\footnotetext{
${ }^{1}$ NYS IPM Program, Cornell University, NYSAES, Geneva, NY 14456 (e-mail: jag7@cornell.edu).

${ }^{2}$ Deceased.
}

1998) and soil texture and bulk density (Ames 1990, Barbercheck and Kaya 1991, Portillo-Aguilar et al. 1999). Entomopathogenic nematodes need high relative humidity to survive and a film of free water for movement. They may become dormant at very low soil moistures. Therefore, moisture conditions have been recognized as one of the most important factors in the soil environment affecting survival, virulence and persistence of nematodes (Klein 1990, Curran 1993).

The goal of our research was to investigate the impact of soil moisture and the compounding impact of soil temperature on the long-term performance of entomopathogenic nematodes. Typically, environmental conditions are static in laboratory studies, but soil moisture levels vary naturally in the field, especially in nonirrigated crops. We simulated this variation by rehydrating soils during the course of each of our laboratory experiments. We hypothesized that nematode-induced insect mortality in rehydrated soil would vary by initial soil moisture content, nematode species and isolate, and time after rehydration. Our first experiment explored differences in the virulence of one isolate of nematode, Heterorhabditis bacteriophora Poinar (Oswego strain), at different soil moisture levels, and the effects of rehydration. The second experiment examined the same effects on several 
nematode species and isolates. The final experiment examined the effects of temperature and soil moisture interactions on rehydration, and tracked long-term nematode-induced insect mortality after rehydration.

\section{Materials and Methods}

Insect Host. Late-instar larvae of the greater wax moth, Galleria mellonella (L.), were used both as hosts for rearing nematodes and as indicators of nematode infection in soil bioassays. Wax moths were supplied by the Sunfish Bait Farm, Webster, WI. Larvae were heat-treated to prevent web spinning, and packed in sawdust for shipping. Once received at our laboratory, wax moths were held at $10^{\circ} \mathrm{C}$.

We used wax moth mortality in our bioassays as a measure of nematode virulence and persistence. Wax moths were placed in nematode-inoculated soil for 3-7 d, depending on the experiment. This exposure is sufficient for nematodes and bacteria to enter and kill insects, but not long enough for nematode progeny to reinoculate the soil (Simoes and Rosa 1996, Boemare et al. 1997).

Nematodes. Five nematode isolates were tested: Heterorhabditis bacteriophora (Oswego strain), $H$. bacteriophora (Tuscarora strain), Steinernema glaseri (Steiner) (NCl strain), S. carpocapsae (Weiser) (NY001 strain), and S. feltiae (Filipjev) (Biosys strain 369 ). Isolates were originally collected in upstate New York (H. bacteriophora [Oswego and Tuscarora strains], and S. Carpocapsae), NC (S. glaseri) and Norway (S. feltiae), and were reared in wax moth larvae following the procedures of Kaya and Stock (1997). Third-instar infective juvenile nematodes (IJs) were harvested from water surrounding White traps (White 1927) within $10 \mathrm{~d}$ of emerging from their hosts.

Soil. Two sandy loam soils (SLA and SLB) were used. They contained 47,46 and $7 \%$ sand, silt and clay for SLA and 60, 30, and 10\%, respectively, for SLB. The soils were 3.3 and $2.8 \%$ organic matter, 7.1 and $5.7 \mathrm{pH}$, 1.25 and $1.29 \mathrm{~g} / \mathrm{cc}$ bulk density, 52.3 and $50.6 \%$ total porosity and 4.8 and $23.7 \%$ aeration porosity, for SLA and SLB respectively. Both soils had a particle density of $2.62 \mathrm{~g} / \mathrm{cc}$. SLA was used for experiment 1, and SLB for experiments 2 and 3 . In all cases, soil was frozen for $48 \mathrm{~h}$ at $-18( \pm 1)^{\circ} \mathrm{C}$ to reduce the population of endemic microbes and microarthropods, and screened twice through 2.36-mm mesh to remove debris and improve uniformity. Soil moisture contents were obtained by weighing and oven drying soil samples (15 \pm $5 \mathrm{~g})$ at $43^{\circ} \mathrm{C}$ (Hillel 1998), and were calculated on a wet weight (wt:wt) basis. Soil moisture adjustments were calculated to raise soil moistures to the target range for each treatment, and the appropriate amount of distilled water was added and mixed into the soil. Soil matric potentials were determined by a filter paper equilibration method (see Kaya and Stock 1997) for specific soil moisture contents. Estimates for SLA were $-60,-9,-6,-1.1$, and -0.5 bar for $6.3,10.2,12.4$, $15.7,18.7 \%$ soil moisture (wt:wt), respectively. Estimates for SLB were $-30,-15,-2$, and -0.1 bar for 6 , 9,12 , and $15 \%$ soil moisture (wt:wt), respectively.

\section{Experimental Design}

Experiment 1: Rehydration from Multiple SoilMoisture Treatments. Twenty-five 480-ml plastic cups $(7 \mathrm{~cm}$ high $\times 10 \mathrm{~cm}$ diameter, Fabri-Kal Corp., Kalamazoo, MI) were filled with soil $(480 \pm 30 \mathrm{~g})$ at each of five soil moisture contents $(6.3,10.2,12.4,15.7$, or $18.7 \%$ wt:wt), for a total of 125 cups. Each cup received 16,900 $\pm 1354 \mathrm{IJs}$ of $H$. bacteriophora (Oswego) nematodes suspended in $1 \mathrm{ml}$ of water and was capped and held in an environmental chamber at 25 $( \pm 1)^{\circ} \mathrm{C}$ and $60 \pm 5 \% \mathrm{RH}$. Once a week for $6 \mathrm{wk}, 5$ wax moth larvae were put on the soil surface in each container, removed after $7 \mathrm{~d}$ and examined for mortality. After the sixth-week bioassay, $15( \pm 5) \mathrm{g}$ of soil were removed from each container for soil moisture determination. At $7 \mathrm{wk}$, the soil moisture in all cups was raised to $14.8 \%$ (rehydrated) for all treatments, based on the individual cup moisture calculations. After rehydration, soil was bioassayed at $9 \mathrm{wk}$.

Experiment 2: Rehydration of Multiple Nematode Isolates from Two Soil-Moisture Treatments. Based on the results from experiment 1 , the range of soil-moisture treatments was narrowed and the number of nematode species and isolates expanded. As in experiment 1, plastic cups (480-ml capacity) were filled with soil $(480 \pm 30 \mathrm{~g})$. Treatments consisted of soil moisture contents of 5.7 and $15.2 \% \mathrm{wt}: \mathrm{wt}$, inoculated with 1 of 5 nematode isolates or a water control.

Nematodes were pipetted onto the soil surface in 1 $\mathrm{ml}$ of distilled water at the following rates of IJ's per cup: H. bacteriophora (Oswego) $(17,500 \pm 1,258), H$. bacteriophora (Tuscarora) $(20,000 \pm 1,333)$, S. feltiae $(9,400 \pm 806)$, and S. carpocapsae $(14,000 \pm 745) . S$. glaseri nematodes $(15,000 \pm 3,225 \mathrm{IJs})$ were delivered in $3 \mathrm{ml}$ of distilled water, because concentrations of this isolate were low. Soil was prepared in three separate batches for both soil moistures to block for potential variation. Each nematode isolate and soil moisture combination consisted of three cups from each soil batch, for a total of nine cups per treatment, resulting in a total of 90 cups. The control treatments were nine cups of low moisture soil and nine cups of high moisture soil inoculated with $1 \mathrm{ml}$ of water. An additional twelve cups (two cups per soil batch) were inoculated with $3 \mathrm{ml}$ of distilled water for comparison with the $S$. glaseri treatments. Containers were capped and held at $25 \pm 1{ }^{\circ} \mathrm{C}$ and $60 \pm 5 \% \mathrm{RH}$.

Bioassays were conducted, at 2, 3, 4, 5, and 6 wk after inoculation. For each bioassay, 10 wax moth larvae were placed on the soil surface per container. After lid replacement, cups were inverted to ensure soil-toinsect contact. Wax moth larvae were removed from the soil after $72 \mathrm{~h}$ and examined for mortality. After the sixth-week bioassay, $15 \pm 5 \mathrm{~g}$ of soil were removed from each container for soil moisture determination. At $7 \mathrm{wk}$, the soil in all cups was rehydrated to $15.3 \%$ and was bioassayed once at $9 \mathrm{wk}$.

Experiment 3: Rehydration of Two Nematode Isolates Under Two Soil Moisture and Three Temperature Combinations. Experiment 3 built on the results of the first two experiments by testing the effect of 


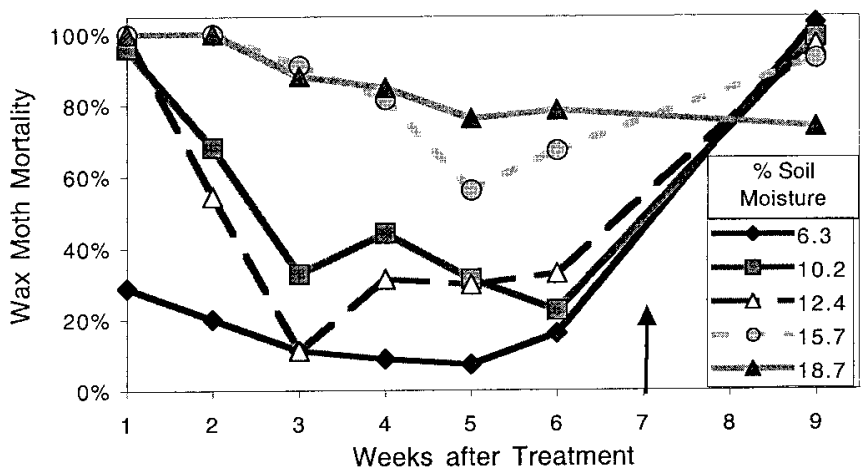

Fig. 1. Wax moth mortality in soils inoculated with H. bacteriophora (Oswego) in experiment 1. Arrow represents rehydration to $14.8 \%$ at $7 \mathrm{wk}$.

temperature and moisture interactions, and by tracking the virulence of rehydrated nematodes for several weeks. Forty-five plastic cups (30-ml capacity, Comet Products, Inc., Chelmsford, MA) were filled with soil $(24 \pm 3 \mathrm{~g})$ at one of four soil moisture contents $(6,9$, 12 or $15 \%$ wt:wt). Each soil moisture level was prepared in three batches, with 15 cups per batch. Distilled water $(0.5 \mathrm{ml})$ containing $273 \pm 29 \mathrm{H}$. bacteriophora (Oswego) IJ nematodes, $265 \pm 32 \mathrm{~S}$. glaseri IJ nematodes, or no nematodes (control treatment) was pipetted onto the soil surface in each cup. Thirty-six additional cups were filled from each soil batch and inoculated with $0.5 \mathrm{ml}$ of water to monitor moisture content. Cups were capped and randomly positioned on aluminum trays, and held at one of three temperatures $\left(20 \pm 1,25 \pm 1\right.$, or $\left.30 \pm 1^{\circ} \mathrm{C}\right)$ and $80 \pm 5 \% \mathrm{RH}$. Soil was prepared in three separate batches per soil moisture and three environmental chambers were used per temperature treatment, to block for potential variation. Each unique treatment combination of nematode species, soil moisture, moisture block, temperature and temperature block was replicated five times, for a total of 1,620 cups.

One wax moth larva was placed on the soil surface in each cup, for each of $4 \mathrm{wk}$. After lid replacement, cups were inverted to ensure soil-to-insect contact and returned to their original positions in the environmental chambers. After a 72-h exposure, larvae were removed from the soil and mortality was recorded. A total of 108 moisture-monitor cups (one cup/soil batch/temperature chamber) were removed weekly for assessment of soil moisture content.

After the fourth-week bioassay, soil from the five $30-\mathrm{ml}$ cup replicates in each treatment was combined in a 120-ml plastic cup (Fabri-Kal Corp., Kalamazoo, MI) to preserve moisture. Four ml of distilled water was added to each cup to raise soil moistures to their original targets of $6,9,12$, or $15 \%$. At this time, temperatures in all chambers were equalized to $25 \pm 1^{\circ} \mathrm{C}$ for the remainder of the experiment.

At $8 \mathrm{wk}$, nematode virulence was bioassayed with 5 wax moth larvae/cup, and a subsample of soil (15 \pm $5 \mathrm{~g}$ ) was removed from each 120-ml cup and assessed for moisture content. Subsequently, the soil in each cup was raised to $15.5 \%$ moisture, based on individual cup moisture calculations. After rehydration, wax moth assays resumed on approximately a weekly basis until insect mortality was $\leq 20 \%$ in all treatments. Two soil samples $(15 \pm 5 \mathrm{~g})$ were periodically removed from each treatment to assess moisture levels. Bioassays continued for a total of $22 \mathrm{wk}$.

\section{Statistics}

Data from all experiments were analyzed using SAS version 6.12 (SAS Institute 1996). Mortality data lacked normality and were therefore, transformed into binomial data by scoring $0-50 \%$ mortality as 0 , and 51-100\% mortality as 1 . Logistic regression analysis was used to compare treatments within each time. Mortality data in each treatment were analyzed over time by the Generalized Estimating equation method (Liang and Zeger 1986), using the GENMOD procedure with the repeated measures statement. No block effects were found for soil moistures (in experiment 2 and 3), or temperatures (experiment 3), so these blocks were removed from the models. Maximum likelihood ratio and Wald $\chi^{2}$ statistics were used to assess significance of various treatment effects. Individual comparisons were always made with one degree of freedom, and significance is reported when $P \leq 0.05$.

\section{Results}

Experiment 1. Insect mortality after $1 \mathrm{wk}$ was at or near $100 \%$ for all soil moistures, except $6.3 \%$, and generally decreased over the next 5 wk (Fig. 1). At 6 wk, insect mortality in the highest-moisture soil (18.7\%) was significantly greater than that in all other soil moistures, and mortality in the $15.7 \%$ soil moisture was greater than the $6.3-12.4 \%$ moisture soils. After rehydration (week 9), insect mortality in soil moistures of $6.3-15.7 \%$ increased significantly to $94-100 \%$. In the highest moisture soil $(18.7 \%)$ insect mortality at $6 \mathrm{wk}$ did not differ significantly from that at $9 \mathrm{wk}$.

Experiment 2. Results from experiment 2 are presented in Fig. 2. Although insect mortality in the control treatments was occasionally high, data are presented to illustrate trends. Statistical comparisons 
A) $5 \%$ Soil Moisture

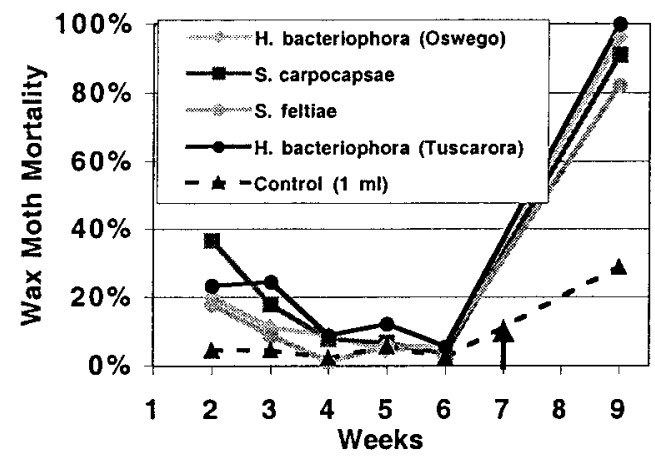

B) $14 \%$ Soil Moisture

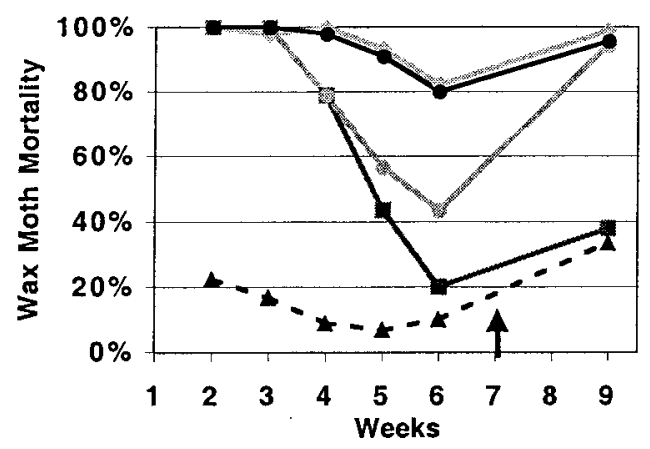

C) $5 \%$ Soil Moisture

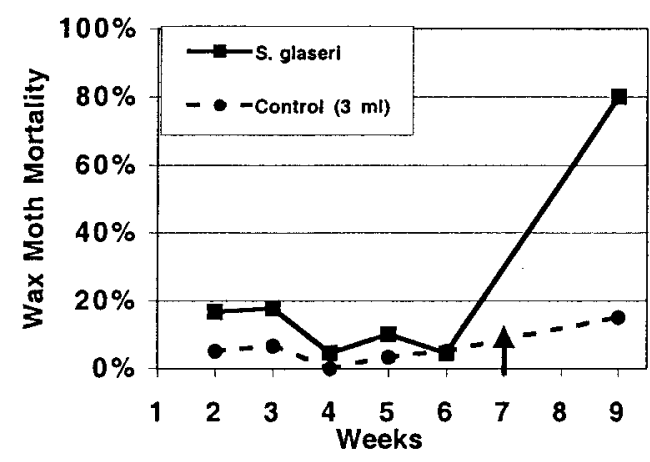

D) $14 \%$ Soil Moisture

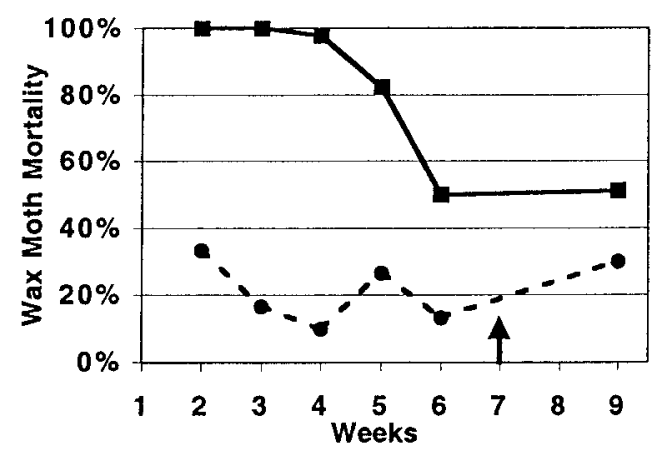

Fig. 2. Wax moth mortality in soils inoculated with various nematode species at two prehydration soil moistures in experiment 2. Arrows represent rehydration to $15.3 \%$ moisture at $7 \mathrm{wk}$.

were only made within a treatment over time, and not among species because the amount of nematodes and water varied. Mortality in the control treatments containing $1 \mathrm{ml}$ and $3 \mathrm{ml}$ of water did not differ significantly from each other, and S. glaseri was compared only to the $3 \mathrm{ml}$ control treatments.

In the $5 \%$ moisture soil, insect mortality in the nematode-inoculated soils did not differ significantly from the controls in weeks 2-6 (Fig. 2A and C). At $9 \mathrm{wk}$ (after rehydration), insect mortality in all four nematode-inoculated soils increased to high levels (75$100 \%)$, significantly higher than week-6 levels and the control at week 9 .

In the $14 \%$ moisture soil, insect mortality was very high (97-100\%) in weeks 2 and 3 for all nematode isolates (Fig. 2B and D). In weeks 4-6, levels declined significantly in S. feltiae, S. carpocapsae, and S. glaseriinoculated soils, and slightly in the H. bacteriophora (Oswego and Tuscarora)-inoculated soils. By week 6, only H. bacteriophora (Oswego and Tuscarora strains) differed significantly from the control. At $9 \mathrm{wk}$ (after rehydration), insect mortality increased significantly from the 6 -wk level in only the S. feltiae-inoculated soils. Insect mortality in the S. carpocapsae and $S$. glaseri-inoculated soils was not significantly higher than the control at $9 \mathrm{wk}$.

Experiment 3. Figure 3 presents insect mortality data by nematode treatment and temperature, cor- rected for control mortality with Abbott's formula (Abbott 1925). The mean control mortality was $5 \pm 5 \%$ and data were not included from bioassay periods when the control mortality was $>20 \%$. In the first three bioassays, insect mortality was greater in the higher moisture soils. At 9 wk (posthydration), insect mortality increased to high levels $(\geq 88 \%)$ in all $H$. bacteriophora (Oswego) treatments, and in S. glaseri treatments at nine and $12 \%$ soil moisture. By weeks 11-19 (depending on treatment), insect mortality in all nematode treatments declined to levels not significantly different from those of the control or each other.

Prehydration (week 2-4), S. glaseri differed from $H$. bacteriophora (Oswego) on only two occasions (12\% soil moisture, $20^{\circ}$, weeks 3 and 4 ). Insect mortality in both S. glaseri and H. bacteriophora (Oswego) treatments was always significantly greater than that in the control in the 12 and $15 \%$ soil moisture treatments, prehydration. In the $6 \%$ and $9 \%$ soil moisture treatments, insect mortality in the nematode-inoculated soils at all temperatures was significantly greater than that in the control in the first bioassay, except $H$. bacteriophora (Oswego) in the $6 \%$ soil moisture treatment at $20^{\circ}$. These levels declined over time and were not significantly different from the control by week 4 . In the six and 9\% soil moisture treatments, insect mortality at all temperatures declined during the ini- 
A. H. bacteriophora Oswego, $20^{\circ}$

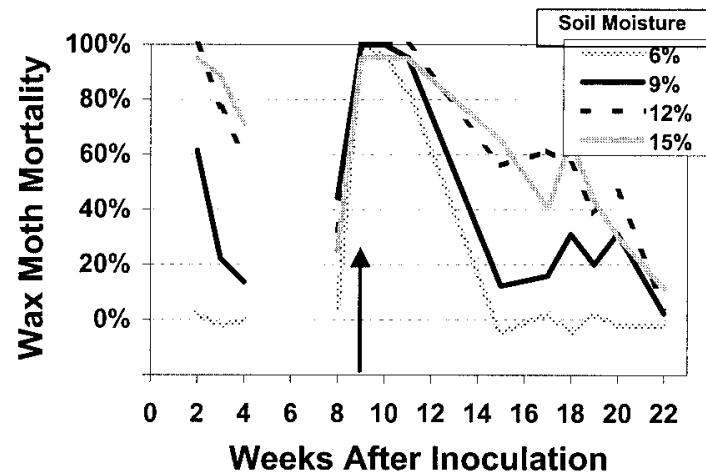

B. H. bacteriophora Oswego, $25^{\circ}$

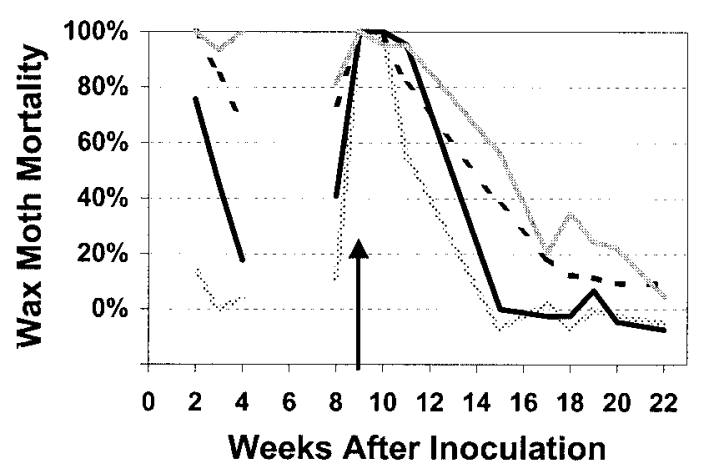

C. H. bacteriophora Oswego, $30^{\circ}$

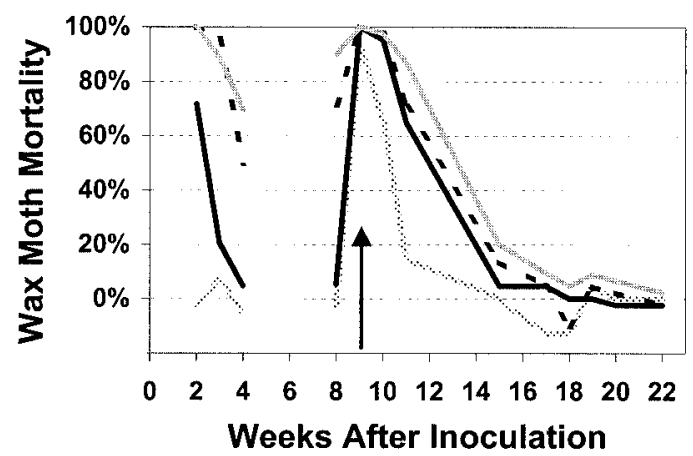

D. S. glaseri, $20^{\circ}$

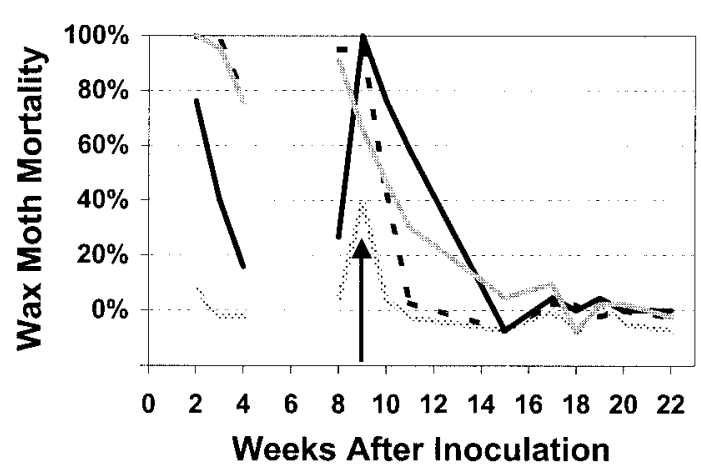

E. S. glaseri, $25^{\circ}$

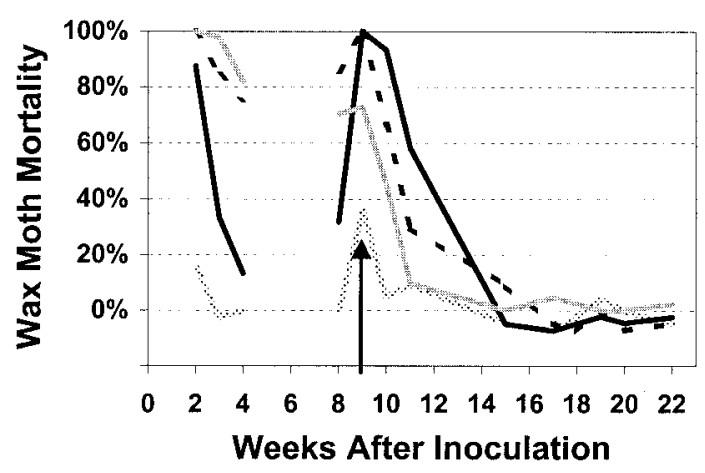

F. S. glaseri, $30^{\circ}$

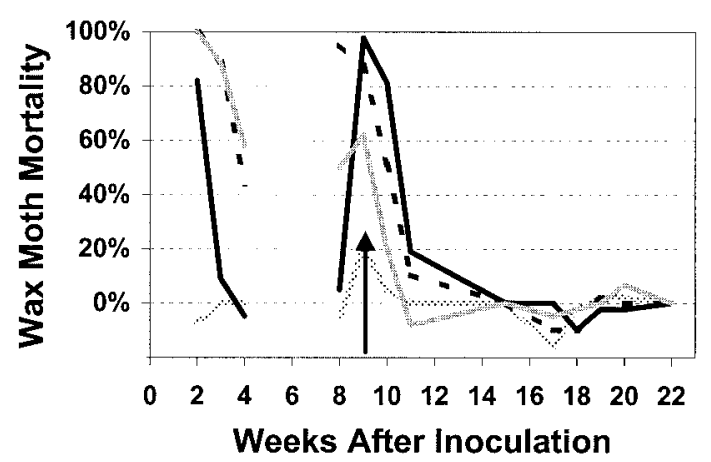

Fig. 3. Wax moth mortality by H. bacteriophora (Oswego) and S. glaseri (NC1) nematodes in experiment 3, comparing soil moisture by temperature. Arrows represent rehydration of soil to $15.5 \%$ after $8 \mathrm{wk}$.

tial month of the experiment and were not significantly different from the control by week 4 .

Insect mortality in the H. bacteriophora (Oswego) treatments at $6 \%$ soil moisture was low $(\leq 12 \%)$ in week 8 but increased to very high levels (93-100\%) after rehydration. S. glaseri-induced mortality was never significantly different from that in the control in $6 \%$ moisture soil, posthydration. In the $9 \%$ moisture soils, insect mortality in both nematode treatments increased to high levels ( $100 \%$ at 9 wk), and was significantly greater than that in the control for several weeks posthydration.

In the higher moisture (12 and 15\%) nematodeinoculated soils at week 8 , insect mortality ranged from 25 to $95 \%$. Mortality increased rapidly posthydration in the case of both nematode species (except S. glaseri in $15 \%$ soil), with H. bacteriophora (Oswego)induced mortality increasing to higher levels, 
which were sustained longer, than that induced by $S$. glaseri.

In weeks 2-4, differences in insect mortality by temperature were usually small and insignificant. Temperatures were equalized to $25^{\circ}$ after the week- 4 bioassay. There were no significant differences associated with the original temperature in weeks $8-22$ in the S. glaseri or control treatments. However, in the posthydration $H$. bacteriophora (Oswego) treatments insect mortality levels were greatest in soils that had been held at cooler temperatures in the early part of the experiment. These differences were more pronounced in the higher moisture soils.

Soil moistures in the prehydration month of the experiment declined from $6,9,12$, and $15 \%$ to $3.9,6.7$, 9.8 , and $12.8 \%$, respectively. Water was added after the fourth-week bioassay to return soils to their target moistures, and at $8 \mathrm{wk}$ all soils were brought to $15.5 \%$ moisture. By the end of the experiment, levels had declined to $12.9 \%$ soil moisture.

\section{Discussion}

Sampling in all of our experiments was conducted in the same nematode-inoculated soils over time. Therefore, we are unable to differentiate among survival and virulence of individuals as opposed to that of the entire nematode population in a container. However, we are still able to observe trends and differences among species. Our results show that differences in soil moisture affect nematode-induced mortality of G. mellonella larvae. We tested soil moistures ranging from below the permanent wilting point of plants to near saturation. These levels represent the full range of soil moistures expected in annual and perennial plantings in the Northeastern United States. In our experiments, nematodes were usually applied at a rate of $\approx 1$ billion IJ nematodes per acre of soil surface area-a commonly recommended field rate. Nematodes were able to infect wax moth larvae at all soil moistures tested and insect mortality increased with moisture content for all nematode species and isolates.

Other researchers have demonstrated differences in entomopathogenic nematode virulence in response to soil moisture in the laboratory (Molyneux and Bedding 1984, Koppenhöfer et al. 1995, Fujiie et al. 1996, Townsend et al. 1998, Duncan and McCoy 2001). Townsend et al. (1998) showed that green June beetle (Cotinus nitida) grub mortality from $H$. bacteriophora and S. carpocapsae nematodes was greater in relatively high moisture (30\%) than in low moisture (10\%) soil. Fujiie et al. (1996) demonstrated that Anomala cuprea larval mortality resulting from S. kushidai infection increased as soil moisture increased from 20 to $40 \%$. The trend of increasing insect mortality with increasing soil moisture in both of these studies agrees with our results. However, it is not possible to compare effects at specific soil moistures because these authors did not report soil matric potentials. A direct relationship between insect mortality and soil moisture was not observed in two other studies, one with $\mathrm{H}$. bacteriophora (D1 strain) and S. glaseri (KG strain) (Moly- neux and Bedding 1984) and one with S. glaseri (NC strain) and S. carpocapsae (All strain) (Koppenhöfer et al. 1995). In these studies, insect mortality resulting from nematode infection was very low or absent in both extremely low and high moisture (nearly saturated) soils. Duncan and McCoy (2001) showed that the nematode $S$. riobrave survived and caused insect mortality best under partial drought conditions. In their work, soil matric potentials differences were imperceptible between full and partial drought conditions, although nematode performance differed. They hypothesize that hydraulic lift by plant roots created localized favorable moisture conditions for the nematodes.

In the field, moisture requirements have been linked to the ability of nematodes to manage insect pests. Irrigation, rainfall, and the resulting fluctuations in soil moisture have been cited as reasons for success or failure (Jackson et al. 1983, Shetlar et al. 1988, Georgis and Gaugler 1991, Selvan et al. 1994). Therefore, irrigation before and immediately following nematode applications are recommended (Shetlar et al. 1988, Downing 1994). Even when these recommendations are followed, however, nematode populations can decline significantly within $1 \mathrm{wk}$ of application (Buhler and Gibb 1994, Sweeney et al. 1998, Duncan et al. 1999)

Several factors may account for the lack of insect mortality in low moisture soil before hydration in our studies. The nematodes may have been dead, immobile, unable to infect insects, or in a quiescent, partially anhydrobiotic state. The ability to quiesce when conditions are unfavorable has been well documented for many plant parasitic and free-living nematodes (e.g., Demeure et al. 1979, Womersley et al. 1998). A quiescent state induced by low moisture is termed "anhydrobiosis," and can be reversed by rehydration. The existence of anhydrobiotic quiescence has been shown for several Steinernema species in air and soil (Kung et al. 1991, Koppenhöfer et al. 1995, Patel et al. 1997) and water-dispersible granules (Grewal 2000), whereas studies on Heterorhabditis species have been restricted to desiccating nematodes for purposes of commercial storage (see Womersley 1990).

The low insect mortality in the drier soils in our experiments may have resulted from quiescing nematodes reducing the pool of active, infective nematodes that could parasitize insects. Similarly, immobility or inability to infect hosts in dry conditions would explain our results. Nematodes in the high moisture soil were not subjected to drought stress, and therefore, were unlikely to quiesce anhydrobiotically. If the increases in insect mortality after hydration were because of reactivation of anhydrobiotic, immobile or noninfective nematodes, we would expect the rebounding effect to diminish at higher original soil moistures. This was true for the highest moisture $H$. bacteriophora (Oswego)-inoculated soil in experiment 1 (Fig. 1), and all nematode isolates except $S$. feltiae in experiment 2 (Fig. 2B). The anticipated diminishing rebound effects also are seen with $S$. glaseri and H. bacteriophora (Oswego) in experiment 3. 
In our experiments, rehydration of soils resulted in dramatic increases in insect mortality. The return of high insect mortality levels after rehydration suggests that low insect mortality levels before hydration were not the result of nematode mortality. Mortality increased similarly for all nematode species and isolates in low moisture soil in experiment 2. However, in experiment 3 in the lowest moisture soils, insect mortality in the $H$. bacteriophora (Oswego) treatment increased to higher levels, and remained higher for a longer period of time, than in the S. glaseri treatment. Our results also show a narrower window for suitable soil moistures for $S$. glaseri than for $H$. bacteriophora (Oswego) nematodes. In addition, the lack of increase in insect mortality after rehydration suggests that the $S$. glaseri nematodes died in the dry soil conditions, whereas $H$. bacteriophora (Oswego) survived. It is possible that $H$. bacteriophora (Oswego) is better able to survive and recover from low moisture conditions than S. glaseri. Alternatively, H. bacteriophora (Oswego) may simply be able to cause insect mortality with fewer IJs than S. glaseri. We cannot distinguish between these explanations, because we did not quantify infection rates.

The long-term virulence of nematodes after rehydration was tracked in experiment 3 . We observed a decline in insect mortality after the initial posthydration bioassay in all nematode treatments, which could be attributable to loss of nematode vigor and/or depletion of the nematodes from the soils. Desiccation and rehydration of nematodes incur high energy costs (Solomon et al. 1999). This may explain the fact that $H$. bacteriophora (Oswego)-induced insect mortality was higher in continually moist soils than in previously dry soils that were rehydrated, in our study. However, in the $S$. glaseri treatments, rehydrated nematodes were the most virulent. Grewal (2000) also demonstrated differences among species-S. carpocapsae and S. riobrave longevity was increased by anhydrobiosis, but that of S. feltiae was decreased.

In our third experiment, nematode-inoculated soils that were originally held at cooler temperatures had greater insect mortality than those held at warmer temperatures. This effect of temperature was more pronounced in the higher moisture soils. Several researchers have documented temperature influences on entomopathogenic nematodes (e.g., Grewal et al. 1994, Townsend et al. 1998, Shapiro et al. 1999). However, to our knowledge, this is the first report of delayed effects. Low temperature is the abiotic factor that most commonly induces facultative quiescence in nematodes (Womersley 1993). If nematode metabolism or mobility were reduced at low soil moisture, temperature would be expected to have the strongest influence in the higher moisture treatments. Our study supports this hypothesis, with the effect of temperature increasing with soil moisture content.

Our studies demonstrated that the virulence of entomopathogenic nematodes in low moisture conditions could be restored by rehydrating the soil. The nematode isolates tested exhibited different optimal ranges for survival and virulence, which were influ- enced by temperature in some cases. Increased knowledge of tolerable soil moisture conditions for nematodes may enable us to better determine if nematode applications will be effective in specific field situations, and to select the most appropriate nematode species and isolates.

Further information needs to be gathered on the effects of soil moisture on nematodes. We need to determine if nematodes in low moisture soils do not infect insects because they have entered a quiescent state, are immobile, or for other reasons. If the nematodes in our studies did not lower their metabolic activities, we would expect them to eventually exhaust their energy supply and die. Therefore, a longer-term investigation that initiates rehydration much later than the 6-8 wk tested in our studies would help answer these questions.

\section{Acknowledgments}

This research was partially funded by the New York State integrated pest management (IPM) program.

\section{References Cited}

Abbott, W. S. 1925. A method for computing the effectiveness of an insecticide. J. Econ. Entomol. 18: 265-267.

Ames, L. 1990. The Role of Some Abiotic Factors in the Survival and Motility of Steinernema scapterisci. University of Florida, Gainesville.

Barbercheck, M. E., and H. K. Kaya. 1991. Effect of host condition and soil texture on host finding by the entomogenous nematodes Heterorhabditis-bacteriophora (Rhabditida: Heterorhabditidae) and Steinernemacarpocapsae (Rhabditida: Steinernematidae). Environ. Entomol. 20: 582-589.

Boemare, N. E., A. Givaudan, M. Brehelin, and C. Laumond. 1997. Symbiosis and pathogenicity of nematode-bacterium complexes. Symbiosis 22: 21-45.

Buhler, W. G., and T. J. Gibb. 1994. Persistence of Steinernema carpocapsae and S. glaseri (Rhabditida: Steinernematidae) as measured by their control of black cutworm (Lepidoptera: Noctuidae) larvae in bentgrass. J. Econ. Entomol. 87: 638-642.

Curran, J. 1993. Post-application biology of entomopathogenic nematodes in soil, pp. 67-77. In R. Bedding, R. Akhurst and H. Kaya [eds.], Nematodes and the Biological Control of Insect Pests. CSIRO, East Melbourne, Australia.

Demeure, Y., D. W. Freckman, and S. D. Van Gundy. 1979. In vitro response of four species of nematodes to desiccation and discussion of this and related phenomena. Rev. Nematol. 2: 203-210.

Downing, A. S. 1994. Effect of irrigation and spray volume on efficacy of entomopathogenic nematodes (Rhabditida: Heterorhabditidae) against white grubs (Coleoptera: Scarabaeidae). J. Econ. Entomol. 87: 643-646.

Duncan, L. W., and C. W. McCoy. 2001. Hydraulic lift increases herbivory by Diaprepes abbreviatus larvae and persistence of Steinernema riobrave in dry soil. J. Nematol. 33: 142-146.

Duncan, L. W., D. I. Shapiro, C. W. McCoy, and J. H. Graham. 1999. Entomopathogenic nematodes as a component of citrus weevil IPM, pp. 69-78. In S. Polavarapu [ed.], Optimal Use of Insecticidal Nematodes in Pest Management. Rutgers University, New Brunswick, NJ.

Fujiie, A., and T. Yokoyama. 1998. Effects of ultraviolet light on the entomopathogenic nematode, Steinernema kush- 
idai and its symbiotic bacterium, Xenorhabdus japonicus. Appl. Entomol. Zool. 33: 263-269.

Fujiie, A., Y. Takata, M. Tachibana, and T. Yokoyama. 1996. Insecticidal activity of an entomopathogenic nematode, Steinernema kushidai (Nematoda: Steinernematidae), against Anomala cuprea (Coleoptera: Scarabaeidae) larvae under different soil moisture conditions. Appl. Entomol. Zool. 31: 453-454.

Gaugler, R. 1988. Ecological considerations in the biological control of soil-inhabiting insects with entomopathogenic nematodes. Agric. Ecosyst. Environ. 24: 351-360.

Gaugler, R., A. Bednarek, and J. F. Campbell. 1992. Ultraviolet inactivation of heterorhabditid and steinernematid nematodes. J. Invertebr. Pathol. 59: 155-160.

Gaugler, R., E. Lewis, and R. J. Stuart. 1997. Ecology in the service of biological control: the case of entomopathogenic nematodes. Oecologia (Berl.). 109: 483-489.

Georgis, R., and R. Gaugler. 1991. Predictability in biological control using entomopathogenic nematodes. J. Econ. Entomol. 84: 713-720.

Georgis, R., and S. A. Manweiler. 1994. Entomopathogenic nematodes: a developing biological control technology. Agric. Zool. Rev. 6: 63-94.

Grewal, P. S. 2000. Anhydrobiotic potential and long-term storage of entomopathogenic nematodes (Rhabditida: Steinernematidae). Int. J. Parasitol. 30: 995-1000.

Grewal, P. S., S. Selvan, and R. Gaugler. 1994. Thermal adaptation of entomopathogenic nematodes: niche breadth for infection, establishment, and reproduction. J. Therm. Biol. 19: 245-253.

Griffin, C. T. 1993. Temperature responses of entomopathogenic nematodes: implications for the success of biological control programmes, pp. 115-126. In R. Bedding, R. Akhurst and H. Kaya [eds.], Nematodes and the Biological Control of Insect Pests. CSIRO, East Melbourne, Australia.

Hillel, D. 1998. Environmental Soil Physics. Academic, San Diego, CA.

Jackson, T. A., B. W. Todd, and W. M. Wouts. 1983. The effect of moisture and method of application on the establishment of the entomophagous nematode (Heterorhabditis bacteriophora) in pasture. Proceedings 36th New Zealand Weed and Pest Control Conference, pp. 195-198.

Kaya, H., and P. Stock. 1997. Techniques in insect nematology, pp. 281-324. In L. A. Lacey [ed.], Manual of Techniques in Insect Pathology. Academic Limited, San Diego.

Kaya, H. K., and R. Gaugler. 1993. Entomopathogenic Nematodes. Annu. Rev. Entomol. 38: 181-206.

Klein, M. G. 1990. Efficacy against soil-inhabiting insect pests, pp. 195-214. In R. Gaugler and H. Kaya [eds.], Entomopathogenic Nematodes in Biological Control. CRC, Boca Raton, FL.

Koppenhöfer, A. M., H. K. Kaya, and S. P. Taormino. 1995. Infectivity of entomopathogenic nematodes (Rhabditida: Steinernematidae) at different soil depths and moistures. J. Invertebr. Pathol. 65: 193-199.

Kung, S. P., R. Gaugler, and H. K. Kaya. 1991. Effects of soil temperature moisture and relative humidity on entomopathogenic nematode persistence. J. Invertebr. Pathol. 57: $242-249$

Liang, K. Y., and S. L. Zeger. 1986. Longitudinal data analysis using generalized linear models. Biometrika 73: 1322.

Molyneux, A. S., and R. A. Bedding. 1984. Influence of soil texture and moisture on the infectivity of Heterorhabditis sp. D1 and Steinernema glaseri for larvae of the sheep blowfly, Lucilia cuprina. Nematologica. 30: 358-365.
Patel, M. N., R. N. Perry, and D. J. Wright. 1997. Desiccation survival and water content of entomopathogenic nematodes, Steinernema spp. (Rhabditida: Steinernematidae). Inter. J. Parasitol. 27: 61-70.

Portillo-Aguilar, C., M. G. Villani, M. J. Tauber, C. A. Tauber, and J. P. Nyrop. 1999. Entomopathogenic nematode (Rhabditida: Heterorhabditidae and Steinernematidae) response to soil texture and bulk density. Environ. Entomol. 28: 1021-1035.

SAS Institute 1996. SAS/STAT Software computer program, version 6.12. By SAS Institute, Cary, NC.

Selvan, S., P. S. Grewal, R. Gaugler, and M. Tomalak. 1994. Evaluation of Steinernematid nematodes against Popillia japonica (Coleoptera: Scarabaeidae) larvae: species, strains, and rinse after application. J. Econ. Entomol. 87: 605-609.

Shapiro, D. I., J. R. Cate, J. Pena, A. Hunsberger, and C. W. McCoy. 1999. Effects of temperature and host age on suppression of Diaprepes abbreviatus (Coleoptera: Curculionidae) by entomopathogenic nematodes. J. Econ. Entomol. 92: 1086-1092.

Shetlar, D. J., P. E. Suleman, and R. Georgis. 1988. Irrigation and use of entomogenous nematodes Neoaplectana spp. and Heterorhabditis heliothidis (Rhabditida: Steinernematidae and Heterorhabditidae) for control of Japanese beetle (Coleoptera: Scarabaeidae) grubs in turfgrass. J. Econ. Entomol. 81: 1318-1322.

Simoes, N., and J. S. Rosa. 1996. Pathogenicity and host specificity of entomopathogenic nematodes. Biocontrol. Sci. Tech. 6: 403-411.

Smith, K. 1999. Factors affecting efficacy, pp. 37-46. In S. Polavarapu [ed.], Optimal Use of Insecticidal Nematodes in Pest Management. Rutgers University, New Brunswick, NJ.

Solomon, A., I. Paperna, and I. Glazer. 1999. Desiccation survival of the entomopathogenic nematode Steinernema feltiae: induction of anhydrobiosis. Nematology 1: 61-68.

Sweeney, J., G. Gesner, R. Bennett, and T. Vrain. 1998. Effect of mulches on persistence of entomopathogenic nematodes (Steinernema spp.) and infection of Strobilomyia neanthracina (Diptera: Anthomyiidae) in fields. Biologic. Microb. Control. 91: 1320-1330.

Townsend, M. L., D. T. Johnson, and D. C. Steinkraus. 1998. Laboratory studies of the interactions of environmental conditions on the susceptibility of green June beetle (Coleoptera: Scarabaeidae) to entomopathogenic nematodes. J. Entomol. Sci. 33: 40-48.

White, G. F. 1927. A method for obtaining infective nematode larvae from cultures. Science 66: 302-303.

Womersley, C. Z. 1990. Dehydration survival and anhydrobiotic potential, pp. 117-137. In R. Gaugler and H. Kaya [eds. ], Entomopathogenic Nematodes in Biological Control. CRC, Boca Raton, FL.

Womersley, C. Z. 1993. Factors affecting physiological fitness and modes of survival employed by daur juveniles and their relationship to pathogenicity, pp. 79-88. In R. Bedding, R. Akhurst and H. Kaya [eds.], Nematodes and the Biological Control of Insect Pests. CSIRO, Canberra, Australia.

Womersley, C. Z., D. A. Wharton, and L. M. Higa. 1998. Survival biology, pp. 271-302. In R. N. Perry and D. J. Wright [eds.], The Physiology and Biochemistry of FreeLiving and Plant-Parasitic Nematodes. CABI Publishing, Wallingford, UK.

Received for publication 2 January 2002; accepted 3 September 2002 